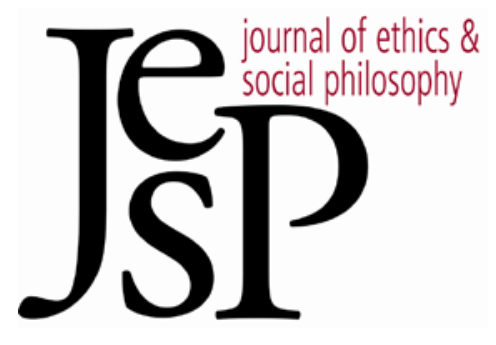

\title{
The Normative Significance of Self
}

\author{
BY DALE DORSEY
}

JOURNAL OF ETHICS \& SOCIAL PHILOSOPHY

VOL. 10, No. 1 | APRIL 2016

URL: WWW.JESP.ORG COPYRIGHT @ DALE DORSEY 2016 


\title{
The Normative Significance of Self
}

\author{
Dale Dorsey
}

NUMBER OF RECENT (AND NOT SO RECENT) WORKS in
the metaethics of practical rationality have suggested that features of
a person's character, commitments and projects have important normative consequences. To see an example of this phenomenon, and with due apologies to Sartre, consider a young man ("Jean-Paul") who is deliberating, at time $t$, about whether to join the Free French, or to remain at home to care for his mother who would otherwise be plunged into despair. ${ }^{1}$ Indeed, one can easily imagine how this sort of deliberation might go: to fight for the resistance is certainly motivated by, among others, reasons of patriotism or self-government, or simply reasons to be rid of the evil of Nazism. To care for his mother is, obviously, motivated by reasons of association or filial duty, reasons generated by his mother's wellbeing.

Assume now that, after deliberation, Jean-Paul privately commits to remaining at home and tending to his mother - to being the devoted son, rather than the dedicated Frenchman. And while all the prior considerations in favor of both options (his mother's wellbeing, reasons of patriotism and so forth) continue to be significant, it also seems right to say that once Jean-Paul has made this commitment - taken on the role or identity of a caregiver - the fact that he has done so seems itself to be significant for Jean-Paul's normative deliberation. At $t_{1}$, it is plausible to say that there is further normative pressure to remain at home with his mother given his commitment, role, identity and so on, undertaken at $t$. Plausibly, and in sum, Jean-Paul faces, at $t_{1}$, a stronger balance of practical reasons to look after his mother rather than to join the resistance than he did at $t$.

Jean-Paul's case is plausibly an example of what I shall call here the "normative significance of self." Different theorists have explored different iterations of this phenomenon, including the normative significance of commitments, ${ }^{2}$ projects, ${ }^{3}$ social roles ${ }^{4}$ or (perhaps most generally) practical identities. ${ }^{5}$ In this paper, I would like to explore the normative significance of self and how best it is to be understood. Typically, views that posit the normative significance of self hold that the content of one's self can create ex nihilo

1 J. Sartre (1956) "Existentialism Is a Humanism," in W. Kaufmann, ed., Existentialism from Dostoevsky to Sartre, Cleveland, OH: Meridian, pp. 295-96.

2 R. Chang (2013a) "Commitments, Reasons, and the Will," in R. Shafer-Landau, ed., Oxford Studies in Metaethics, Vol. 8, Oxford: Oxford University Press, pp. 74-113.

3 B. Williams (1974) “A Critique of Utilitarianism," in J. J. C. Smart and B. Williams, Utilitarianism: For and Against, Cambridge: Cambridge University Press; (1981) "Persons, Character, and Morality," in Moral Luck, Cambridge: Cambridge University Press, pp. 1-19.

${ }^{4}$ K. Manne (2013) "Being Social in Metaethics," in R. Shafer-Landau, ed., Oxford Studies in Metaethics, Vol. 8, Oxford: Oxford University Press, pp. 50-73.

${ }^{5}$ C. Korsgaard (1997) The Sources of Normativity, Cambridge: Cambridge University Press. 
practical reasons to behave in particular ways. I argue that this suggestion cannot be plausibly sustained - facts of self do not give rise to practical reasons. However, or so I also argue, we can salvage the normative significance of self via an alternative mechanism. Facts of self do not create new reasons but instead indicate those reasons to which particular persons are especially susceptible - they strengthen preexisting reasons.

A note: I will continue to refer to Jean-Paul's case as a plausible instance of the normative significance of self. You might reject this either on grounds that the self has no such normative significance or on grounds that this case is not a very good representation of it. Fair enough. My interest, however, is in providing the best account of the normative significance of self - not defending the general phenomenon. And if you do not like my case as an instance of it, you are free to substitute one you would prefer.

\section{The Normative Significance of Self}

Many theorists of practical reason have accepted a version of the normative significance of self, as I understand it here. The locus classicus is Christine Korsgaard's suggestion that an individual's practical identity can give rise to practical reasons and normative obligations:

An agent might think of herself as a Citizen of the Kingdom of Ends. Or she might think or herself as someone's friend or lover, or as a member of a family or an ethnic group or a nation. She might think of herself as the steward of her own interests, and then she will be an egoist. Or she might think of herself as the slave of her passions, and then she will be a wanton. And how she thinks of herself will determine whether it is the law of the Kingdom of Ends, or the law of some smaller group, or the law of egoism, or the law of the wanton that will be the law that she is to herself. ... Practical identity is a complex matter and for the average person there will be a jumble of such conceptions. You are a human being, a woman or a man, an adherent of a certain religion, a member of an ethnic group, a member of a certain profession, someone's lover or friend, and so on. And all of these identities give rise to reasons and obligations. Your reasons express your identity, your nature; your obligations spring from what that identity forbids. ${ }^{6}$

More recently, Ruth Chang has argued that "commitments" can give rise to new reasons for action (here a commitment should be understood as distinct from a promise, 7 in the sense that someone might commit to a person, such as a spouse or lover, or a project, such as saving the rainforest). Chang presents the example of a commitment one makes to a person, Harry. She writes:

Your commitment to Harry essentially involves your willing that his interests be reasons for you to do things. Commitments are essentially volitional activities. When

\footnotetext{
${ }^{6}$ Korsgaard (1997: 101).

7 Chang insists that commitments in her sense are "very much an internal affair" (2013a: 76-

77). In this way, commitments are distinct from promises, which require external uptake.
} 
you will that some consideration is a reason, you "stipulate" or "command" - by a sheer act of will - that it be a reason. ... When you make a commitment to Harry, you will his interests to be reasons for you to do things. ${ }^{8}$

Here my commitment to Harry makes his welfare a reason for me to act.

Kate Manne suggests something similar when it comes to social roles and practices. Manne writes:

Social practices are evidently rich, complex, and varied in their nature. How, though, could they be a source of practical normativity? How, in other words, could social practices actually generate practical reasons? On (what I take to be) the most natural way of developing this idea, the norms of a social practice will take on genuine, normative force under certain conditions, which render the practice as a whole valid. ...We will say (most naturally) that desires can generate reasons for an agent to fulfill her desires, much as I have said here that social practices can generate reasons for participating agents to conform to its norms. 9

For Manne, the relevant conditions under which particular social roles or social practices generate reasons require that the agent be involved in the practice. ${ }^{10}$

Finally, and perhaps most famously, Bernard Williams suggests (though does not quite state explicitly) that an individual's most significant ground projects can give rise to practical reasons (reasons, specifically, to carry on living). Williams writes:

This point once more involves the idea that my present projects are the condition of my existence, in the sense that unless I am propelled forward by the conatus of desire, project and interest, it is unclear why I should go on at all. ... A man may have, for a lot of his life or even just for some part of it, a ground project or set of projects which are closely related to his existence and which to a significant degree give a meaning to his life. ... The consequences of that for practical reasoning (particularly with regard to the relevance of proximity or remoteness in time of one's objective), is a large question which cannot be pursued here; here we need only the idea of a man's ground projects providing the motive force which propels him into the future, and gives him a reason for living. ${ }^{11}$

As Williams notes, a person's central projects help to define who he or she is, and consequently give rise to practical reasons to "go on at all."

Though these views are importantly different, ${ }^{12}$ they certainly bear a family resemblance. Generally, I will refer to these views as accepting the norma-

\footnotetext{
8 Chang (2013a: 93).

9 Manne: 55.

10 Manne: 63. Manne also insists that the social practices are generally conducive to human flourishing. I will discuss the second condition in more detail later.

11 Williams (1981: 12-13).

12 For views with similar upshots, see M. Betzler (unpublished manuscript) "Why Value Personal Projects?”; S. Buss (2006) "Needs (Someone Else's), Projects (One’s Own), and Reasons," Journal of Philosophy 103(8): 373-402; D. Portmore (2007) "Welfare, Achievement, and
} 
tive significance of self: when I make a commitment, take on a project, adopt a certain role, etc., this fact changes the sort of person I am. ${ }^{13}$ Views that accept the normative significance of self will hold that changes in a person's self which, again with apologies to Sartre, I will call "existential changes" - have normative effects of the sort described in Jean-Paul's case. Of course, not everyone will agree that all aspects of self have normative significance. Some will accept the normative significance of commitments, others of projects, roles and so on. This paper will not adjudicate that issue (with one minor exception - see n. 44), but will instead treat views of this kind under the same general heading; the reader is free to focus on her preferred normatively significant feature of the self. (One clarificatory note: there is a sense of the term "commitment" that does not imply anything like a feature of self as I have been understanding it. One can say, for instance, that I am "committed" to seeing the earliest possible showing of Star Wars: The Force Awakens, where this amounts to something like a very strong intention. However, in this paper, I am interested in the sense of commitments qua facts of self: features of my character, practical identity and so on. Indeed, the commitments Chang is most interested in clearly fall into the latter category. ${ }^{14}$ )

Though the argument of this paper need not rest on this claim, I do not think it is ridiculous to suggest that the normative significance of self is required to plausibly account for Jean-Paul's case. As an alternative, one might suggest, for instance, that in making the relevant decision Jean-Paul faces a new practical reason given, say, his prudential interest, or his particular desires or pro-attitudes. But these explanations seem cheap: it certainly need not be the case that Jean-Paul is made better off by remaining at home for him to face additional normative pressure to do so given his existential change. Furthermore, though we may accept the normative significance of desire or proattitude, to make reference solely to such explanations in Jean-Paul's case just seems wrong. It may be that, at $t_{1}$, Jean-Paul lacks any preference to remain home with his mother rather than joining the Free French. He may be simply indifferent, or may continue to be in the grip of existential angst. But the fact that he committed to doing so at $t$ seems to generate the relevant normative pressure (even, in my view, an obligation).

One might also attempt to explain Jean-Paul's additional reason to remain at home given the widely recognized normative force of, e.g., promises, expectations and so forth. But this cannot be the whole story. One might imagine, for instance, that Jean-Paul has not explicitly promised his mother to do anything. He has simply decided to remain at home. Of course, one might create a sort of reason-providing expectation without doing so explicit-

Self-Sacrifice," Journal of Ethics and Social Philosophy 3; C. Calhoun (2009) "What Good Is Commitment?" Ethics 119(4): 613-41.

13 To put this in a slightly different way, to make a commitment, take on a social role or take on a project are ways of establishing or modifying one's practical identity.

14 Chang (2013a: 76-77). 
ly.15 But, first, implicit expectations seem less plausibly normative than expectations that are generated via an explicit commitment or promise. After all, if I walk down the street at the same time every day, it is perfectly justified for my neighbor to expect me to do so in the future, and hence to plan his sidewalk-cleaning activities on this basis. But it would be implausible to say that I have any additional reason to do so despite the fact that my neighbor is justified in expecting me to do so. (That is, a reason generated by the expectation. I may have a reason to alleviate inconvenience, and hence may have a reason to stick to what my neighbor expects given that he may be put out if I do not; but the reason to stick to that which my neighbor expects is at best derivative.) Second, and perhaps more importantly, imagine that, in addition to not actually making a promise or assuring his mother, Jean-Paul's mother is a cynical sort. She has seen the longing Jean-Paul has to join the resistance and simply believes that at some point or other he is going to take off and leave her alone. Even if his mother were of this sort of attitude, it seems wrong to say that Jean-Paul lacks the stronger practical reason not to join the Free French at $t_{1}{ }^{16}$

Alternatively, one might suggest that the normative effects for Jean-Paul at $t_{1}$ can be explained by the normative significance of Jean-Paul's intention (say, to care for his mother), formed at $t .{ }^{17}$ Note that there is substantial debate concerning whether intentions have these sorts of normative effects. ${ }^{18}$ Abstracting from that here, I doubt whether the significance of intentions

15 See, for instance, T. M. Scanlon (1990) "Promises and Practices," Philosophy and Public Affairs 19: 200-1.

16 Indeed, this forms an important criticism of Scanlon's account of the moral force of promising. See, for instance, S. Schiffrin (2008) "Promising, Intimate Relationships, and Conventionalism," Philosophical Review 117(4): 481-524. One could finesse the view, of course. Perhaps it is the case that Jean-Paul's mother has a justified expectation that Jean-Paul will remain, despite the fact that there is no implicit or explicit promise on Jean-Paul's part, and despite the fact that she does not actually expect him to remain. (Thanks to Derrick Darby for a helpful discussion of this point.) But the problem here is to give an adequate interpretation of "justified." One could say, for instance, that Jean-Paul's mother is justified in expecting Jean-Paul to remain because Jean-Paul has an obligation to do so. But this is, obviously, an inadequate explanation of said obligation. Alternatively, one could say that Jean-Paul's mother is, perhaps, epistemically justified in expecting her son to remain. Two problems arise. First, we have no reason to believe it is true. Perhaps, for instance, Jean-Paul has decided to stay home again and again, only to pack his bags and take off every time. In this case, his mother is certainly not epistemically justified in expecting him to remain. But Jean-Paul's sordid history is no reason to believe he lacks an obligation to remain, given his decision. Second, this proposal seems to run into the same one faced by the "implicit expectation" proposal: I lack an obligation, or even any practical reason, to conform to my typical rounds simply on the basis that my neighbor is epistemically justified in expecting me to do so (rather than, say, to alleviate inconvenience for my neighbor).

17 Consider M. Bratman (2012) “Time, Rationality, and Self-Governance," Philosophical Issues 22(1): 73-88. For Bratman, the normative significance of intention is given by reasons of "self-governance."

18 For problems that concern the normative significance of intention, see J. Brunero (2007)

“Are Intentions Reasons?” Pacific Philosophical Quarterly 88(4): 424-44. 
could fully underlie our response in Jean-Paul's case. To begin with a small point, even if past intentions have present normative force, the normative force of intention seems to explain some plausibly, normatively significant features of self (such as commitments) better than others (social roles, say). More importantly, however, while the fact of intentions could, in principle, explain some normative force of Jean-Paul's existential change (assuming the presence of the relevant intention), the normative significance of self seems to operate independently of any particular normative significance of intention. One can form intentions, even very strong intentions, that do not constitute facts of self. But those intentions that do help to form the sort of person you are, as it were, seem to have additional normative significance beyond the mere fact of an intention. The fact that Jean-Paul intends to look after his mother may be normatively significant at $t_{1}$. But the fact that he not only intended, but committed, took on a social role, a practical identity and so forth, seems to be of independent normative consequence. Thus, even if all existential changes involve intention, I doubt that the normative significance of intention could allow us to jettison the per se normative significance of self.

Of course, for all this you might reject the suggestion that the normative significance of self is the only way to explain Jean-Paul's $t_{1}$ normative landscape. C'est la vie. But at the very least, the normative significance of self is a plausible account of the practical reasons Jean-Paul faces at $t_{1}$, and hence deserves further exploration.

\section{Creationist Accounts}

Trouble is on the horizon. The standard account of the normative significance of self, as indicated by the views of Chang, Korsgaard, Manne and Williams, holds that facts about an individual's self (such as their projects, commitments, practical identities and so forth) create or give rise to new reasons. (I will refer to such accounts as "creationist" accounts.) In other words, given that, at $t_{1}$, I maintain a particular normatively significant feature of my self that I lacked at $t$, I now face a practical reason at $t_{1}$ that I did not face at $t$.

In this section I would like to explore what I take to be a set of problems for the explanation of the normative significance of self in terms of reason-creation. None of these problems are knockdown, in the sense that they show creationist accounts incoherent on their face, say. But creationist accounts seem to violate first-order considered judgments about the reasons people have, both prior to and subsequent to the initiation of a fact of self, an existential change. To introduce the general problem, consider Chang's view. Chang claims that "[y]our commitment to Harry essentially involves your willing that his interests be reasons for you to do things." ${ }_{19}$ But this claim is strange: Harry's interests are reasons for everyone to do things, and surely

${ }_{19}$ Chang (2013a: 93). 
one has a reason to promote Harry's interests or otherwise take them seriously even prior to one's commitment. It would be absurd to say that the fact that Harry's interests would be promoted is not a reason for me to act, even if I have not committed to him. And hence a commitment surely does not generate this reason: the reason was already there.

So far I have offered a first-order intuition: Harry's interests are reason for everyone to act. But this claim calls for additional argument. First, consider what practical reasons do. (Or, perhaps, consider one of the things practical reasons do.) They justify action. If I had a legitimate practical reason to $\phi$, this seems to entail that, other things being equal, there is at least some justifying force in favor of $\phi$-ing. Absent countervailing reasons, one ought not to blame me for $\phi$-ing, I ought not feel guilt for $\phi$-ing and so on. However, in the absence of any particular reason to $\phi$, one could not justify one's $\phi$ ing to any degree whatsoever. To lack a reason to $\phi$ seems to entail that there is nothing counting in favor of one's $\phi$-ing at the relevant time. But imagine, for instance, that a person who has not committed to Harry, perhaps does not even know Harry, happens to benefit him in some way. Perhaps he simply picks Harry's name randomly out of the phone book and performs some action that makes Harry better off. What would we think of this person's action? Could it not be justified to any degree? Perhaps there are better ways this person could be spending his time and/or resources. But to say that this person's action has nothing counting in favor of it is simply implausible. ${ }^{20}$

So for creationist accounts to be plausible, it must be that the fact of self can give rise to some new reason to act. But what could these new reasons be? The answer is simple, really. Reasons, after all, are facts, facts with particular normative significance. If this is right, there are only two ways to create new reasons. The first is to newly imbue a (potentially) preexisting, but norma-

20 Perhaps a creationist account could be circumscribed. Instead of saying that facts of self create any sort of reason to perform an action (including justifying reasons), one might instead say that the requiring force of reasons is or can be created by facts of self. This might be plausible in Harry's case. Though everyone has a justifying reason to benefit Harry, perhaps only those who commit to Harry have a reason that has the power to require action to benefit him. (Note that to divorce the justifying and requiring force of practical reasons is controversial. See, for instance, J. Gert (2007) Brute Rationality, Cambridge: Cambridge University Press, ch. 2. I will simply assume it for the sake of argument here.) However, this claim also seems implausible. Imagine that with no effort whatsoever - the mere push of a button one could cure Harry of a very painful, long, terminal illness. I find it extremely plausible to say that the person who fails to act in this way acts contrary to what he ought to do, whether or not the person in question has so committed. We would certainly blame this person for not acting; we would think that guilt would be appropriate for not acting and so forth. If this is correct, it would appear that there must be requiring reasons to benefit Harry, even for those who have not committed. Of course, it may seem quite plausible to say that the strength of such reasons varies: if I have committed to Harry I face stronger reasons to benefit him. And while this is plausible - as I explore at length in $\int 3-$ it does not concern the creation of practical reasons. 
tively inert, fact with normative significance. ${ }^{21}$ Chang seems to suggest this mechanism: the fact that $\phi$-ing would benefit Harry surely predates (or could predate) one's commitment to Harry. But, in committing (or so suggests Chang), one renders this previously non-normative fact normative. According to the second possibility, existential changes bring into existence a normative fact. But what changes between $t$, in Jean-Paul's case, and $t_{1}$ ? Presumably, just the relevant fact of self, viz., the fact that Jean-Paul has committed, or taken on a social role, etc. And hence, in this case, the fact of a particular feature of self just is the reason for action.

\subsection{Old Facts, New Reasons}

Start with the first possibility. On this account, the normative pressure JeanPaul faces, at $t_{1}$, to look after his mother must be the result of some normatively inert fact that predates (or could predate) Jean-Paul's existential change at $t$, but that is rendered normatively significant by this existential change. But I think there are two problems here.

First, the proposal on the table appears to be over-inclusive: it grants too much power to existential changes. For the proposal to work, it has to be the case that the particular reason-giving or reason-providing fact that captures the normative significance of self must have no normative significance prior to its encapsulation as part of one's self (i.e., as a commitment, social role, etc.). Otherwise the power of a fact of self to create new reasons would be moot. What would such facts look like? Surely not about anyone's wellbeing, the goodness of consequences, rights, respect, autonomy - no matter how insignificant. (This seems to be the problem with Chang's view, cited above.) Surely not about justice, social cohesion, human flourishing, knowledge - no matter how insignificant. Surely no fact that had prudential or aesthetic significance - no matter how insignificant. These facts, like Harry's interests, seem to plausibly give rise to reasons independent of commitment - surely, e.g., aesthetic value can be used to provide at least some justificatory force in favor of actions, even absent the fact that one is an artist, say.

What we require, then, is a case in which there seems to be a fact of no antecedent normative significance that could be rendered significant given facts of self. I suppose one could commit to the preservation of a certain rock, say. (And here I do not mean the preservation of Monument Valley, but of, quite literally, a pebble that one entirely lacks any antecedent reason to preserve.) Would this commitment create a reason to do so? In other words, would the fact that one committed to the rock render "this rock would be preserved by $\phi$-ing" a reason to $\phi$ ? I do not think so. The fact that the rock would be preserved would most likely be understood as a sign of

${ }^{21}$ I say "potentially preexisting" because the relevant fact could come into existence simultaneously with the existential change, but not because of the existential change, yet be imbued with normative significance only because of the existential change. 
rank irrationality or mental illness. (One might say that folks who so commit would have a desire to preserve the rock, and hence may have reason to do so. This is fine with me, but would not explain such reasons given the normative significance of self, but rather of pro-attitude.) Plausibly, you have reason to preserve the rock given a commitment to do so only under the condition that there is already some normatively significant feature of the rock prior to the commitment (say, its aesthetic or environmental importance).

In response, one might consider certain religious or community rituals and traditions. For instance, the fact that it is a Friday during Lent seems not to be a fact with independent normative significance - indeed, paradigmatically so. But it would seem quite important to an observant Catholic - this fact would itself be a reason not to eat meat today. And hence existential changes can imbue previously existing facts with new normative significance. However, I think this is mistaken. We can and should make a distinction between intrinsic and derivative reasons. Derivative reasons surely vary from person to person. The fact that this is a trumpet is not a reason for just anyone to pick it up and play it - only trumpet players. But insofar as "this is a trumpet" is a reason for trumpet players to pick it up is simply derivative, derivative of a more fundamental reason, e.g., to advance aesthetic value. It just so happens that the unique contribution of trumpet players to aesthetic value is to play the trumpet - the reason granted by the fact that this is a trumpet is simply derivative. Plausibly, this is what occurs in the case of religious observance. If would be odd to say that the intrinsic reason not to eat meat on Fridays during Lent is that it is a Friday during Lent. If in fact there is such a reason - which I will just assume for the sake of argument here - it is more likely to be, e.g., the fact of conforming to community norms one has internalized, or perhaps even more straightforwardly to advance one's wellbeing, or observe commands of the deity. To put this another way, whatever reasons Catholics may have not to eat meat on Fridays during Lent, the reason most assuredly is not the bare fact that it is a Friday during Lent, this fact is at best normatively derivative.

There is a second problem with the first mechanism. The normative significance of self seems to extend to folks whose commitments, say, or practical identities involve things that are very clearly antecedently reason-giving. Take Jean-Paul. Plausibly, in remaining at home, Jean-Paul takes on a commitment, or a social role, that is dedicated to his mother's wellbeing. But, as noted already, Jean-Paul surely has practical reason to advance his mother's wellbeing even in the absence of this commitment - indeed, as noted above in response to Chang's "Harry" case, surely anyone has such a reason. ${ }^{22}$ But if

22 One might again simply accuse me of pounding the table against views according to which all practical reasons are a result of the normative significance of self (such as, e.g., Korsgaard). But (a) I have already argued that these facts should be reasons independent of the specific content of one's self and (b) even Korsgaard accepts that anyone - whatever their specific conception of self - must accept a general value of humanity (cf. Korsgaard 1997: 125, 143). And hence, for Korsgaard, everyone will have a reason to benefit Harry, 
this is true, to insist that the normative significance of self is to create reasons via imparting normative significance to (potentially) antecedently existing nonnormative facts is to say that the normative significance of self is inert in cases in which reasons are already there. But this is absurd! Surely, as an artist, I face additional normative pressure to respond to aesthetic considerations. But these considerations are already reason-giving for anybody. And hence if the normative significance of self functions only to impart normative significance to previously existing (or in principle previously existing) nonnormative facts, it cannot explain this pressure.

\subsection{New Facts, New Reasons}

The first proposal does not succeed. But there is a second: it could be that the fact of some aspect of a person's self brings into existence a new fact imbued with normative content. But what could this be? What new fact arises given an existential change? The answer seems to be the fact of this aspect of selfhood. This very clearly solves the second problem above: surely aesthetic reasons exist. But if I am an artist, I face additional normative pressure to advance aesthetic beauty because the fact that I am an artist is a reason for me to do so.

I offer two arguments against the suggestion that facts of one's self are reasons for action in this sense. First, recall the justifying force of practical reasons. If there were not already reason to $\phi$, it would seem particularly strange to refer to a person's existential change in favor of $\phi$-ing as itself providing justificatory force. We would not, for instance, hold that a Nazi prison guard's commitment to Hitler's cause would provide any exculpatory force, as we must if commitments themselves are reasons for action. (Of course, on no plausible view is the Nazi prison guard going to be all-thingsconsidered justified. But my claim is different: it seems entirely strange to believe that there is anything of justifying strength to be had in the fact of such a commitment.) Indeed, imagine the following dialogue: Accuser: "You acted wrongly in serving as a Nazi prison camp guard!" Accused: "I admit that. But I deny that there was nothing to be said for doing so. After all, I was committed to Hitler's cause?' The response of the accused in this case would be little more than a sick joke. Surely the fact that someone was committed to Hitler's cause is not justifying. If anything, it is evidence that this person is far less justified than someone who merely acted out of a momentary whim. If all this is correct, we should reject the claim that facts of self of this kind can themselves be reasons for action.

There are two potential ways to respond to this argument. The first is to simply bite the bullet. This is Korsgaard's strategy.23 Of the "mafioso," she

even absent a "Harry-centric" conception of self. This is true even though, for Korsgaard, facts of self are the source of all practical reasons.

23 Korsgaard (1997: 251-58). 
concludes that he does, in fact, have practical reasons derived from his practical identity (such as practical reasons to make his enemies sleep with the fishes). Needless to say I find this difficult to swallow, but I will leave it as an open option for now.

A second possibility, which I will discuss in more detail, is offered by Kate Manne. ${ }^{24}$ According to Manne, one of the conditions under which an individual is given new reasons by participation in a particular social role or practice is that this social role or practice is "reasonably conducive to general human flourishing." ${ }_{25}$ (I will concentrate on social roles here, but one could trivially translate this proposal for any normatively significant feature of self.) For Manne, that the relevant social role is reasonably conducive to human flourishing is not itself a reason, but instead plays the role, familiar from holist accounts of moral rationality, of an "enabler." 26 The fact of self (say, that one has taken on a certain role) is the reason, but only under conditions that this particular fact of self meets the condition of being conducive to general flourishing. However, I find this proposal unconvincing: I deny that the fact that a particular practice is reasonably conducive to general human flourishing is not itself an antecedent practical reason (in holist terms, a "favorer" rather than enabler). Surely I could justify performing the relevant action (or, at least, partially justify doing so) by noting that the action in question contributes to a practice that itself is conducive to human flourishing.

Manne might deny this: as she rightly notes, there are some particular actions that would not be generally conducive to flourishing but that nevertheless one has reason to perform given that they are part of a practice that is, in fact, reasonably conducive. ${ }^{27}$ And, if this is right, only those who take on the relevant roles have such reasons. But I think this analysis is mistaken. Consider the notion of the "telos" of a social practice or role. Roughly speaking, the idea is this: the telos of a social practice or role is the normative explanation or justification of the existence of the practice in question. The telos of the practice of marriage is, for instance, the wellbeing of the couple, stable family dynamics and so forth. The telos of, e.g., the role of department chair is the health of the department, the furtherance of the goals of the university, etc. Now consider the following suggestion. Assume that a particular social practice or role $S$ passes Manne's test, viz., is "reasonably conducive to gen-

${ }^{24} \mathrm{~A}$ third possibility is inspired by some suggestions by Korsgaard. She seems to suggest that a constitutive element of autonomous agency is conformity to the categorical imperative (see, for instance, Korsgaard (2009) Self-Constitution: Agency, Identity, and Integrity, Oxford: Oxford University Press, pp. 25-26). So it could be that one simply cannot (autonomously) commit, or take on a social role, etc., without so conforming, and hence commitments like those above could be avoided. (Thanks to an anonymous reviewer for suggesting this possibility.) I find this suggestion implausible on its face, but will not engage it insofar as the "new facts, new reasons" proposal remains problematic even if we accept this reading of Korsgaard.

${ }^{25}$ Manne: 63.

${ }^{26}$ Cf. J. Dancy (2004) Ethics Without Principles, Oxford: Oxford University Press.

27 See Manne: 64. 
eral human flourishing." Under these conditions, either it is the case that a particular action $\phi$ furthers the telos of $S$ or it does not. If it does, then even if $\phi$-ing itself does not further human flourishing, it surely does so indirectly, viz., by furthering the telos of a social practice or role that is generally conducive to flourishing (such as the welfare of particular couples, the success of a department, the goals of a university and so on). This is certainly a reason for anyone to act: to contribute to the success of a social practice generally conducive to human wellbeing. This reason may only rarely be decisive. But it is surely a reason. Alternatively, it may be that $\phi$-ing does not further the particular telos of $S$. If so, it is hard to see why anyone, even those participating in the role, would have a reason to $\phi$. After all, it is contrary to the role's telos.

What does all this have to do with Manne's response? It would appear that the fact that a particular social practice is generally conducive to human flourishing is itself a reason in favor of actions that contribute to the telos of that practice (or role) - reasons for anyone. (If an action does not contribute to its telos, even the relevant feature of selfhood would not generate a reason to perform it.) But if so, it would appear that Manne's suggestion that only social roles that are generally conducive to human flourishing create reasons for action cannot be sustained. To do so would be to require that the fact of being so conducive is an enabler, rather than a favorer. But, or so it would appear, the reverse is true. And hence if this is correct, creationist accounts (insofar as they subscribe to the present mechanism) must posit a sui generis reason, e.g., the fact of $\mathrm{X}$ (where $\mathrm{X}$ is a social role or other fact of self) whatever it is. ${ }^{28}$ But if this is right, the first problem for the "new facts, new reasons" mechanism remains.

However, even if everything I have just said is incorrect, the "new facts, new reasons" mechanism seems to me to face a second, decisive, objection. To suggest that the fact of self is itself a reason for action seems to me poorly reflective of normative experience. In committing to his mother, Jean-Paul (plausibly) ought to care for his mother rather than fight for the resistance. But what reasons do we make reference to in explaining this purported obligation? Compare:

First. Jean-Paul's reason to spend time looking after his mother rather than fighting for the resistance is the fact that in so doing he would be conforming to his social role, following his practical identity, etc.

28 One might argue that this inference is not justified. Could there not be other "validity" conditions that are not properly thought of as favorers? This is perhaps so, but I remain skeptical. Here's an argument for this skepticism: to do their job, the relevant validity conditions should rule out the "bad" facts of self (Nazi prison guard) and rule in the "good" facts of self (spouse, friend, artist). But it is hard to see how to distinguish the bad facts of self from the good ones if not on the basis of what it is that makes the good ones good and the bad ones bad. But whatever it is that makes the good ones good will count in favor of advancing the telos of that social practice in the way that I have illustrated here. 
Second: Jean-Paul's reason to spend time looking after his mother rather than fighting for the resistance is the fact that his mother's welfare would be advanced by doing so. This is especially important for him because be has committed to her wellbeing, he's her caregiver, he is a devoted son, etc.

I claim that Second is far more natural. When asked to justify Jean-Paul's continuing commitment to his mother, we are tempted to say just that his mother's wellbeing is more significant in importance for him than it would be for just anyone. Of course, we may explain this fact by pointing to his commitment to remaining at home, his social role, etc. But these facts are not themselves reasons. Rather, or so it would seem, in justifying Jean-Paul's action we refer to the base-level facts to which caregivers are responsive. If asked why Jean-Paul should be more sensitive to these reasons, or why these reasons should determine how he should act, rather than the average would-be resistance fighter, we are likely to cite his decision to remain at home, his social role, etc. Given his role, we would say, of Jean-Paul, that his mother's wellbeing "looms large." I take this to mean that, for Jean-Paul, his mother's wellbeing is more significant as a reason than it would be given this reason's default strength.

Indeed, consider a particular action Jean-Paul takes in keeping with his social role. Perhaps his mother is in the grip of sadness; he goes out to procure her a nice meal to take her mind off her troubles. Let's imagine that we ask Jean-Paul to justify his doing so. Surely he would respond with something like this: "The meal will make her feel better; she has been having a particularly tough day today." When asked why this fact should matter to him rather than some stranger, he would be likely to say: "I am her son! I am her caregiver! I have committed to her wellbeing!" and so forth. But this latter set of facts would rarely be used in and of themselves to justify his buying her the meal. To use these facts as reasons in and of themselves seems to me a creepy form of self-involvement. ${ }^{29}$ To say "I am her caregiver" when looking for a justification for buying her a nice meal should always understood as elliptical: "It would make her feel better, and it matters for me to do so because I am her caregiver."

${ }^{29}$ Notice that just this sort of an objection is avoided by Mark Schroeder in rejecting the "no background conditions" account of a subjectivist theory of practical reasons. According to critics, a subjectivist view is creepy in just this way: "Such a view commits agents who are deliberating well and non-enthymematically to taking what Mark Johnston calls the pornographic attitude: they are moved only by considerations about the satisfaction of their own desires," (Schroeder (2007) Slaves of the Passions, Oxford: Oxford University Press, p. 27; the Johnston citation is Johnston (2001) "The Authority of Affect," Philosophy and Phenomenological Research 63(1): 201). For Schroeder, the better view is to hold that reasons need not make any reference to the person in question (27-30). Put in terms of the normative significance of self, to hold that the reason that exists given the fact of an existential change is the fact itself seems to entail a problematically self-obsessed attitude: I am a caregiver becomes the reason, rather than my mother's welfare will be affected. The better view, or so I claim, is to hold that the reason in question is the fact of an effect on Jean-Paul's mother's welfare, but that this reason is not created by the existential change, but strengthened by it. 
Once again, one might try to respond to my skepticism of the "new facts, new reasons" mechanism by reference to, e.g., religious traditions. Could it not be the case that one of the reasons for me not to eat meat on Fridays during Lent is the fact that I am Catholic? I doubt it. Consider an analogous case. Imagine that I become a fan of the Toledo Mud Hens. ${ }^{30}$ When people ask me: "Why are you wearing that Mud Hens T-shirt?" "Why are you paying for Mud Hens season tickets?" and so on, I might very well answer "I am a fan!" And, indeed, the fact that I am a fan of the Mud Hens likely entails that I have reasons to go to their games that other people do not. But the fact that I am a fan of the Toledo Mud Hens cannot in and of itself plausibly constitute a reason for me to engage in these actions. Imagine that, though I am a fan of the Mud Hens, I have no desire to go to their game today, I would not get any enjoyment out of it and so on. It would hardly be plausible to say that other things being equal I have an obligation go to the game simply because I am a fan. Similarly, if, though Catholic, there are no internalized community norms, my welfare will not be advanced, I am not acting on command of a deity and so forth that would constitute independent reasons to refrain from meat-eating on relevant Fridays, it would be implausible to say that, nevertheless, one still has a reason to refrain from carnivorism on the relevant days, viz., the fact that one is Catholic.

Ultimately, it is most plausible to say that the reasons that tell in favor of, e.g., my not eating meat on Fridays during Lent just are reasons that we all face: reasons to, e.g., advance one's own wellbeing, reasons of community participation and so on. The reasons for me to go to Mud Hens games are reasons of enjoyment, the fact that I desire to do so. The fact that I am Catholic (or a Mud Hens fan) merely helps to indicate what sorts of activities will advance my welfare or will allow me to participate in important community rituals (or what sorts of activities will advance my pleasure or enjoyment, or what activities I actually desire to engage in). These - like derivative reasons - will vary from person to person.

\section{Self and the Strength of Reasons}

The previous reflections convince me (and I hope the reader) that the normative significance of self is not best understood via creationist accounts. However, or so I shall argue here, this does not spell the end of the normative significance of self. My proposal: the normative significance of self is an instance of a capacity to strengthen preexisting reasons.

This proposal has prima facie plausibility. Consider again Second. When Jean-Paul takes on the role of, say, caregiver to his mother, this appears to be a fact of tremendous normative significance for him. But it would be strange to hold that the new reason just is that "Jean-Paul is the caregiver." The additional normative pressure generated by taking on this role is instead ex-

30 Thanks to an anonymous reviewer for offering a similar example. 
plained by the fact that because Jean-Paul is his mother's caregiver, her wellbeing generates stronger reasons for him to act than were he not her caregiver. $\mathrm{He}$ is especially susceptible to those reasons given the relevant fact about the content of his self. If, for instance, I have committed to being an artist or if being an artist is part of my practical identity, it will surely be the case that I have greater reason to, say, advance beauty than others. But this is not because the fact that I am an artist is itself a reason for me to act. It is because as an artist I am more normatively susceptible to aesthetic considerations than those who are not - aesthetic reasons are stronger for me than for nonartists.

Which reasons are strengthened? Plausibly, if one's practical identity is to be an artist, the fact that one is an artist ought to strengthen aesthetic reasons. If one is committed to science, this commitment ought to strengthen reasons of knowledge acquisition. Putting all this together, reasons strengthened by facts of a person's self are reasons to which that particular feature of self is responsive. What does this mean? Take a certain conception of self, S. S, in my view, is responsive to all and only those reasons to which people who are $\mathrm{S}$ respond in virtue of being $\mathrm{S}$. Reasons to which, say, artists are responsive are those reasons to which artists respond in virtue of being artists, viz., aesthetic reasons. The reasons to which devoted sons are responsive are those to which devoted sons respond in virtue of being devoted sons. Take JeanPaul. His commitment to remain home with his mother might very well be supported by a wide variety of reasons. But the reasons to which Jean-Paul's self is responsive are all and only those reasons that devoted sons and caregivers are responsive to in virtue of maintaining that feature of self - in this case, plausibly, his mother's welfare. Furthermore, devoted sons may respond to many reasons - aesthetic reasons, reasons of friendship and any others for that matter. But they will not respond to these reasons in virtue of this fact of self. To put this together, then, my proposal is that existential changes are normatively significant to the extent that features of one's self prioritize or strengthen practical reasons to which those features are responsive. To borrow, as Manne does, a touch of holist terminology, here facts of self or existential change play the role of an intensifier of preexisting reasons.

In addition to its prima facie plausibility, my proposal is superior to creationist accounts. First, it can obviously explain the normative significance of self in cases in which the reasons in question hold prior to the existential change - on my view, only such existential changes are normatively significant. Second, because the normative significance of self only strengthens preexisting reasons, there is no danger of newly generated reason to pursue activities that are normatively unsavory in themselves. My commitment to becoming a Nazi prison camp enforcer generates no additional normative pressure to follow through on that commitment - there is no reason in favor of so doing. Because existential change only prioritizes extant practical reasons, any conception of self that is not responsive to such reasons will not be normatively significant. Third, there is no danger of the particular fact of self being treated (wrongly, in my view) as itself the reason to act in accordance. 
Rather, the reasons to act in accordance just are those reasons to which this feature of one's self is responsive. They just apply to you in a special (stronger) way given that you maintain that conception of self.

At this point, I should compare my proposal to one offered by Chang. According to Chang, there are certain cases in which particular values can be in what she calls "equipoise": when "one fails to have more, less, or equal reason to choose one alternative over the other." 31 And in such cases of equipoise, Chang claims that one has the power to render particular options rationally required - determinative of what one should do. This view is to some degree similar to mine, but should be distinguished on two grounds. First, Chang (as noted already) specifically insists that the reasons in question are new reasons - reasons we create by an act of will.32 I have already had occasion to dispute this, and will not do so again here. But one could, of course, interpret Chang's claim not as insisting that the relevant act of will (commitment, say) brings new reasons into existence, but rather simply strengthens preexisting reasons. ${ }^{33}$ But, perhaps more importantly, I see no justification to restrict the power of individuals to strengthen such reasons merely to those cases in which these reasons are in "equipoise." 34 Two reasons strike me as important here. First, if we allow that reasons can be strengthened, to restrict the normative significance of self in this way seems to me ad hoc. Why, if reasons can be strengthened, can they be strengthened only when the other reasons one faces are of a similar strength? Second, Chang's proposal seems to me wrong on first-order grounds. Imagine, for instance, that just for any ordinary person the reasons in favor of caring for Jean-Paul's mother and in favor of contributing in some small way to the war effort tilted slightly in favor of the war effort, just barely enough to render the reasons not in "equipoise." But should this, then, mean that Jean-Paul's commitment to his mother makes no normative difference? I find this quite implausible. The fact that Jean-Paul has committed to his mother, taken on the relevant social role and so forth, seems to me to render it at least not irrational in such a case to look after his mother, perhaps even rationally required. ${ }^{35}$

31 R. Chang (2013b) “Grounding Practical Normativity: Going Hybrid,” Philosophical Studies 164(1):163-187, 178.

32 Chang (2013b: 178-79). She calls these "voluntarist" reasons rather than "given" reasons.

33 Of course, Chang would reject this suggestion, as she holds that given reasons and their strength are "metaphysical" constraints on the normative effects of, e.g., commitment (2013b: 178). So she would not allow that an act of will could alter the given strength of particular given reasons. But I will leave this aside here.

34 Again, as in the previous note, it should be granted here that Chang's own view offers a rationale to believe that voluntarist reasons should be restricted. But this rationale applies only if one believes what one is doing is creating new reasons, not strengthening preexisting reasons. If we are strengthening already existing reasons, why restrict our capacity to do so simply to those cases in which our reasons are in equipoise?

35 While Sartre's exegesis is beyond the scope of this paper, it is interesting to note that some passages in Sartre seem to indicate that he accepts something like the view I am sketching. He says, for instance, "If values are uncertain, if they are still too abstract to determine the 
Despite my differences with Chang's approach, my account of the normative significance of self is broadly flexible and ecumenical. First, it is ecumenical between substantive theories of practical reason. Take any theory. This theory will assign certain normative valences to certain facts that will tell in favor of certain actions. My claim is that this theory - whatever that theory is - can be understood as providing the right account of the creation or explanation of practical reasons, reasons that can then be strengthened or weakened by the capacity understood here. ${ }^{36}$ Of course, my view is not going to be compatible with an account of practical reason that denies the normative significance of self as I understand it. But it is compatible with any theory of practical reasons that are thereby strengthened. Further pursuant to this point, my proposal is compatible with both the acceptance or rejection of socalled "existence internalism" about reasons (i.e., the claim that reasons must find an "internal resonance" in the persons to whom they apply). ${ }^{37}$ It is perfectly possible to insist that all practical reasons must pass a test of internalism but also hold that other facts beyond the extent to which an individual endorses such reasons can strengthen their normative significance. 38 Here is another way to put this point: as I have been at pains to argue, we do not have the capacity to create reasons on the basis of the normative significance of self. This normative significance is the power to strengthen extant reasons. But existence internalism is a necessary condition on the existence of reasons (hence "existence" internalism). But my proposal is entirely neutral on the question of what gives rise to practical reasons in the first place (beyond my

particular, concrete case under consideration, nothing remains but to trust in our instincts" (296-70). He seems to be expressing here that, in Jean-Paul's case, while some considerations count in favor of fighting and of staying at home, they are too uncertain or "abstract" to settle on what should be done. In this case, we have "our instincts," which may very well strengthen the considerations in favor. If so, then my position should be thought of as in agreement with Sartre. Thanks to an anonymous reviewer for this helpful point of comparison.

36 One might note that accepting something like a subjectivist theory of practical reasons might be in tension with my claim that my account can avoid strengthening reasons to which Nazi prison camp guards are responsive. After all, depending on how reasons are generated, there may very well be such reasons. Of course, this may be correct. But, or so I argue, this is not a problem for my account, but is instead a good reason to reject a creationist account that allows such reasons to exist. My proposal is superior to a proposal that treats facts of self as giving rise to reasons because my proposal is not thereby committed to the existence of abhorrent reasons given an abhorrent aspect of self.

${ }^{37}$ See Williams (1981) "Internal and External Reasons," in Moral Luck, op. cit.; C. Korsgaard (1986) "Skepticism about Practical Reason," Journal of Philosophy 83(1): 5-25, esp. 23.

38 This is not to say that all who accept existence internalism will allow that a person's desires merely give rise to, rather than also determine the strength of, individual practical reasons. It is merely to say that the latter claim is a further thesis that need not be accepted by someone who accepts existence internalism, which is clearly a constraint on the existence, not strength, of a reason. 
rejection of the claim that facts of self do), and hence is perfectly compatible with existence internalism or any other theory of how reasons come to be. ${ }^{39}$

In addition, this theory is ecumenical when it comes to the precise contours of the normative significance of self. Whether you accept that commitments, roles, practical identities, projects, participation in practices, etc., maintain normative significance (or whether you choose to mix and match), this normative significance can, and I argue should, be understood as a method to strengthen or intensify reasons, not to generate them. Furthermore, you could adopt or reject any number of potential contours of the normative significance of self. For instance, Korsgaard makes reference to two tests that practical identities must pass to be normatively significant. She writes: "The conception of one's identity in question here is not a theoretical one, a view about what as a matter of inescapable scientific fact you are. It is better understood as a description under which you value yourself, a description under which you find your life to be worth living and your actions to be worth undertaking." ${ }^{40}$ Here it would appear to be that not only must you recognize the particular feature of yourself - you must be able to understand yourself as, e.g., a devoted son and caregiver - but you also must value this feature of yourself. You could accept either of these proposals, or neither, or one or the other. You might vary these requirements depending on the particular feature of self (i.e., perhaps social role does not require recognition or valuing, but maybe practical identity does). It is up to you. My view is fully neutral on these questions.

Finally, we might naturally wonder about the extent to which the reasons in question are strengthened. If, say, the proper conception of my self is of someone who is devoted to my mother's welfare, does this entail that I am practically obligated to look after my mother come what may? Again, the proposal in favor of which I argue could be interpreted in many different ways on this point. But, crucially, this priority need not be overwhelming. For instance, though a particular person may be an artist, and therefore rightly prioritizes aesthetic reasons, they may be required not to conform to such reasons if the balance of competing reasons is strong enough. Tonya Harding lacked sufficient reason to organize the attack on Nancy Kerrigan, despite the fact that doing so may very well have been the action most called for by the reasons to which her figure-skater self were responsive, i.e., reasons to compete at the highest level (assuming, contrary to fact, that Kerrigan's injury would have paved the way for Harding's nomination for the 1994 Olympic team). For this reason, it is also not the case that individuals are "locked in" to conforming to prioritized reasons for, say, the rest of time. One might

${ }^{39}$ My point here is similar to one by Mark Schroeder - for Schroeder, an internalist conception of reasons is an account of the grounding of reasons: the ultimate explanation of what makes facts normative. But it need not be that the particular weight of reasons passes the relevant tests of agential resonance. See Schroeder (2007) "Weighting for a Plausible Humean Theory of Reasons," Noûs 41.

40 Korsgaard (1997: 101). 
hold that, given his existential change at $t$, Jean-Paul is required at $t_{1}$ to remain with his mother rather than simply changing his mind and running off to join the resistance. But even if he faces this sort of a requirement at $t_{1}$, it need not hold if circumstances change: if the circumstances of the resistance become much more dire or if it turns out that his mother is in danger of much less serious despair than she had been. With a change in the given strength of reasons that tell in favor of joining the Free French or remaining at home, this can render a decision to join the resistance rational, even assuming JeanPaul's existential change at $t$. Again, however, the precise strength of reasons so strengthened by the normative significance of self is something that will await further consultation with considered judgment.

\section{Objection: Conflict and Priority by Mistake}

John Brunero argues against the claim that an individual's intentions provide reasons. Now, I have already argued that the normative significance of self is independent of the normative significance of intention. But Brunero's objection to the latter proposal may be instructive here, nonetheless. According to Brunero, if intentions provide reasons, this can yield incoherent normative commands:

How are the reasons provided by intentions supposed to be weighed against what we normally take to be reasons in an effort to come to an all-things-considered conclusion about what ought to be done? It would be possible, on this view, for it to be the case, supposing I intend to go to Grand Central Station, that I ought not intend to go and I ought to go - that is, my intention could go against the balance of reasons, thereby making it the case that I ought not intend to go, but still count as a reason to perform the intended action, and thereby tip the scales in favor of going. ${ }^{41}$

To see the form of Brunero's worry for my view, note that it may be irrational or impermissible of me to commit to some particular thing, but nevertheless be required of me to follow through, given the normative significance of self as I understand it here. Imagine that Jean-Paul's decision to assist his mother is normatively impermissible. Imagine that his mother will experience only mild annoyance if he does not stay at home, and that the Free French deeply need him to pave the way for the Allied invasion of Normandy. Under these conditions, to remain at home would be a mistake. But the mere fact that it is a mistake does not alter the fact that it changed the content of his self, potentially rendering remaining at home what he ought to do, despite the fact that he ought not to so commit.

I agree that my view holds the possibility of separating the permissibility of the existential change itself from the permissibility of following through

${ }^{41}$ Brunero: 427-28. Note that Brunero's argument seems to focus on a creationist account, viz., the fact of my intention counts as a reason to perform the intended action. But this finer detail is neither here nor there for present purposes. 
on the new fact of self. But I deny that this is a problem. One can imagine that practical reason requires Jean-Paul to join the Free French rather than to care for his mother. We would say, under such conditions, that his commitment could not be normatively justified. But given this commitment, would we say that he acts wrongly in continuing to look after his mother? "No" is a perfectly appropriate answer here: though his original decision is a mistake, the concerns that nevertheless tell in favor of caring for his mother exert a more powerful form of normative authority given his new feature of self. Though this entails a kind of conflict, it need not be a particularly problematic one: "You should not have taken on this role," we may be tempted to say to Jean-Paul, "but since you did, you should probably stick around." Notice that Brunero's worry seems far more pressing for the view according to which intentions provide reasons. It would be odd to say, e.g., that "you should not have intended to do that, but you should have done it nonetheless," whereas it is much less odd to say that "you should not have committed to that, but given your commitment, you should follow through."

\section{Objection: Promising, etc.}

A further objection ${ }^{42}$ notes that, in fact, there are a number of recognized ways that we can give rise to new practical reasons - some of which can coincide with, or even help to constitute, existential changes. And if that is correct, surely existential changes can give rise to new reasons.

For instance, take a promise. One way to understand the normative force of promises is that the act of promising generates new practical reasons to act. Perhaps the fact that I have promised $x$ that I will $\phi$ is itself a reason for me to $\phi$. (And hence promising seems to take the "new facts, new reasons" shape discussed in $\ 2$ 2.2.) If I promise that I will go bowling with you on Saturday, though there may be many reasons for me to do so independently of the promise, the fact that I have promised itself seems to be a reason to go. Though this account of the normative force of promises is certainly controversial, I will simply assume it for the sake of argument here. But, and here is the objection, surely it is the case that promises can give rise to existential changes! For instance, I might promise my mother on her deathbed that I will, despite my many years of neglect and listlessness, finally put my talent to good use and become an artist. Surely that promise gives rise to an existential change, if anything does. And hence should not the fact, then, that I have undertaken this existential change create a new reason, given that this existential change is the result of a reason-creating promise?

I think the typical answer here is "no." The fact that I have promised my mother seems of itself not to change the content of my self. Notwithstanding my general ecumenical treatment of "selfhood," facts of self seem to include general facts about the sort of person I am, my basic values and projects

42 Thanks to an anonymous reviewer. 
(commitments, identities, etc.). And hence a mere promise seems neither necessary nor sufficient to give rise to an existential change - to do so would require some further change (e.g., a social role or commitment) that, of itself, would seem entirely sufficient to establish the relevant fact of self. 43

That is, with perhaps one exception. Promises may give rise to certain social roles. It could be that "oaths of office" are like this. One could imagine that I am not the president of the United States, for instance, until I am sworn in - until I have made a promise to uphold the Constitution, and so forth. Could these sorts of oaths or vows not give rise to an existential change, viz., the fact that I am president? Perhaps. But even if so, this does not entail that facts of self generate new reasons. We can and should make a distinction between the normative force of the oath and the normative force of the fact of self, viz., that I am president. Any new reason I have as a result of taking the oath of office seems to be given by the fact that I made a promise or a vow (if, controversially, this is the best way to understand promises), not the fact of self, viz., that I am the president. One might put this point in general terms. We can and should distinguish between the fact of self and whenever promises are involved - the promise that gives rise to this fact of self. But given this, like the normative significance of intention (see $\int 1.1$ ), it is possible to distinguish the per se normative significance of a promise and the per se significance of a fact of self. And while it is true that some promises may accompany or even give rise to facts of self, any new reason so created will not be generated by the fact of self, but instead by the promise. Any new reason I have, e.g., to execute the duties of my office faithfully is not the fact that I am president (fact of self), but the fact that I promised to do so. The fact that I am president - the fact of self - instead explains the greater significance any extant reasons may exert on my rational decision-making - the welfare of the citizens of my nation and so forth. ${ }^{44}$

This may seem like splitting hairs, but it is of the essence. So far I have been trying to explain and accommodate the normative significance of self, i.e., some important feature of the sort of person I am or take myself to be. For a creationist account of this phenomenon to succeed, the fact of some

43 As I suggested earlier, projects, commitments and social roles all seem to be ways to shape our practical identities; promises, in and of themselves, do not. See n. 13.

${ }^{44}$ A rejoinder: could it not be that some promises themselves are facts of self? Just as, e.g., a commitment to Harry's wellbeing could be an existential fact about me, could a promise to Harry not be the very same thing? And while I mean to be generally ecumenical concerning what constitutes a self or practical identity, here I wish to resist. Facts of self, paradigmatically, seem to include our commitments, significant social roles, projects - those things that make up our practical identities. But I find it difficult to believe that a promise could itself constitute such a fact of self independently of some other change (such as a new social role or internal commitment). Certainly existential changes can happen alongside promises, and may even be prompted by promises. But there is, once again, good reason to distinguish the normative effect of promising from the normative significance of self as I have understood the latter concept here. (Similar comments are relevant for, e.g., intentions and wrongdoing; see below.) 
existential change, some feature of my self or the sort of person I am must be essential to the explanation of the existence of some particular reason. But even if we accept that promises can (sometimes) give rise to an existential change, the facts of self seem to drop out in an accounting of the new reasons one has - in other words, one does not have to make reference to the fact that this particular promise gives rise to a fact of self to explain the promise-generated reason. Rather, one merely makes reference to the promise. ${ }^{45}$

The point explored here is worth generalizing. There may, in fact, be many ways that we can generate new reasons. It may be that promising is one way. Maybe intending is another way. It may be that, having deliberately wronged you, I now face new reasons to apologize or to make amends (e.g., the fact that I have wronged you seems a plausible reason to do so). But in each of these cases, there is good reason to distinguish the normative upshot of, e.g., intentions, wrongdoing and facts of self. And since we have so far seen very good reason to reject the reason-generating capacity of facts of self, there is good reason to retain the suggestion that facts of self qua facts of self do not themselves generate reasons - though we can certainly give rise to new reasons in other ways.

\section{Objection: Pro-Attitude}

One might reject my attempt to explain the normative significance of self in the following way. "Look," or so it might be said, "surely it is the case that desires, pro-attitudes and so forth can themselves generate or give rise to reasons. Indeed, you seem to allow this possibility yourself in declaring that your view is neutral with regard to existence internalism. But why should it be the case that desires or pro-attitudes can generate reasons, but facts about self cannot? After all, surely it is the case that facts about my self are 'deeper,' a more significant picture of my normative outlook than mere desires or proattitudes."

This is an important objection. Of course, nothing in what I have said requires you to accept the authority of desires or pro-attitudes to create or otherwise explain the existence of practical reasons. You might reject the normative authority of self qua reason-creator and then also proceed to reject the authority of pro-attitude qua reason-creator for similar or even the same reasons. That is OK with me. Of course, this is more or less the objection. Many people hold that it is extremely plausible to believe that pro-attitudes

${ }^{45}$ Furthermore, it is worth noting that what I take to be the most serious problem facing the "new facts, new reasons" mechanism as applied to facts of self seems to be largely mitigated in the case of promises. It is surely the case that to treat the fact that I have promised $x$ to $\phi$ as a reason to $\phi$ is not creepily self-involved. And there is a good reason for this: facts of self, in Chang's language (2007a: 76-77), seem internally directed; promises are externally directed; and hence to reference the bare fact of a promise in justifying action seems not to require the same sort of self-involvement as simply to reference a fact of self. 
give rise to reasons, and hence, if there is pressure to reject this thesis given a rejection of the suggestion that the normative significance of self can give rise to reasons, this might be as solid a reductio as you could find. After all, if you do not think that a commitment or practical identity would ground a reason to be a Nazi prison guard, why believe that a mere desire would do so? Furthermore, whatever else this objection entails about the normative significance of self as I have understood it, such reflections would certainly entail a rejection of the ecumenical comments made in $₫ 3$.

However, I do not believe this is the case. At this point, my argumentative burden is merely to indicate that there is at least some rationale to accept both the reason-generating role of pro-attitude and the merely strengthening role of self. And, furthermore, this rationale need only be plausible to those who are antecedently attracted to the reason-generating capacity of proattitude. And here it is: facts about one's self - such as one's commitments, social roles and so forth - and the capacities to shape our selves, such as those explored here, seem to me paradigmatically capacities that are responsive to particular practical reasons. Indeed, this is indicated by the standard rationales for taking on features of one's self (for committing, taking on a project or practical identity): I take on some social role or commitment not willynilly but as a result of normative deliberation, because I believe that to which I am committing, e.g., is important. Jean-Paul considers the importance of both his mother's interests and the interests of the Free French, and decides to commit to his mother's wellbeing because it is in itself normatively significant. (The same holds had he decided to join the Free French.) I become an artist not just because I happen to like art, but rather in part (at least) given the inherent significance of aesthetic beauty (significance that might very well be imparted by my own pro-attitudes). And so on. Of course, not everyone will take on aspects of self as a result of such normative deliberation. And sometimes this deliberation will be faulty (such as in the Nazi prison guard case). But the standard case seems to me illustrative: we typically treat features of one's self as being the product, at least in part, of one's normative deliberation, of one's capacity to assess the importance of that to which one is, e.g., committing.

However, it could be that pro-attitudes are different. For instance, when I develop a pro-attitude toward watching baseball, it would be odd to say that this pro-attitude is responsive to those attitude-independent reasons I have to watch baseball if I also claim that the reason I have to watch baseball is generated by this very pro-attitude. Thus, those who would imbue desires with reason-generating authority will typically hold that these desires are not sensitive to attitude-independent reasons in favor of the object of said attitude, but instead give rise to those very reasons. But taking on an aspect of self is something that is responsive, or ought to be responsive, to the importance of that to which one is, e.g., committing. Of course, many people reject the 
claim that pro-attitudes are not responsive to reasons in this way.46 But that is neither here nor there. Those who accept the reasons-creating authority of desire are typically attracted to this position because they hold that desires give rise to reasons rather than respond to them. But whether or not pro-attitudes are responsive to reasons, it is extremely plausible to believe that facts about one's self are. Whether or not my reflections are plausible, they are sufficient to deliver the ecumenical nature of my proposal - ecumenical, that is, between views according to which pro-attitudes (such as desires) create or otherwise explain the existence of reasons and those that do not.

\section{Conclusion}

The fact that I have taken on a commitment, maintain a particular social role, have a particular practical identity and so forth, are all plausibly facts of self that in themselves maintain normative significance. Indeed, this normative significance is plausibly required to explain a number of important cases like Jean-Paul's. The project of this paper, however, is to come to a more precise understanding of the mechanism by which facts of self alter our normative landscape. We should reject, or so I argue, the suggestion that the normative significance of self creates reasons, either by imbuing (potentially) preexisting facts with normative significance, or by holding that facts of self are themselves reasons for action. Rather, it is more plausible to say that facts of self, facts about the sort of people we are, pick out certain reasons as applying to us in a special way, as having greater force for us than for those who do not share our social role, projects or practical identity. The welfare of Jean-Paul's mother is a reason for anyone to act. But the fact that Jean-Paul is his mother's devoted son, her caregiver, entails that his mother's welfare is a far stronger reason for him than for anyone else.

Dale Dorsey

Department of Philosophy

University of Kansas

ddorsey@ku.edu

46 See, most importantly, T. M. Scanlon (1999) What We Owe to Each Other, Cambridge, MA: Harvard University Press, ch. 1; D. Brink (2008) "The Significance of Desire," in R. ShaferLandau, ed., Oxford Studies in Metaethics, Vol. 3, Oxford: Oxford University Press, pp. 5-46. 